\title{
Post Operative Sensorineural Hearing Loss Following Middle Ear Surgery-A Study of 100 Cases
}

\author{
Antony Abraham Paulose, Ajeet Kumar, Nishi Sonkhya* \\ Department of Otorhinolaryngology \& Head and Neck Surgery, SMS Medical College \& Hospital, Jaipur, Rajasthan, India \\ Email: *mikepaulose@yahoo.co.in, ${ }^{\star}$ drsonkhya@yahoo.co.in
}

How to cite this paper: Paulose, A.A., Kumar, A. and Sonkhya, N. (2018) Post Operative Sensorineural Hearing Loss Following Middle Ear Surgery-A Study of 100 Cases. International Journal of Otolaryngology and Head \& Neck Surgery, 7, 67-74.

https://doi.org/10.4236/ijohns.2018.73009

Received: March 9, 2018

Accepted: May 5, 2018

Published: May 8, 2018

Copyright $\odot 2018$ by authors and Scientific Research Publishing Inc. This work is licensed under the Creative Commons Attribution International License (CC BY 4.0).

http://creativecommons.org/licenses/by/4.0/

c. (i) Open Access

\begin{abstract}
Background: Drill and surgical tools can cause noise induced hearing loss when used on or adjacent to the ossicular chain and stapes footplate or while working on the mastoid bone. Therefore the drill generated noise has been incriminated as a cause of sensorineural hearing loss in the operated ear. Objective: This study has been undertaken to estimate the proportion of sensorineural hearing loss following middle ear surgery and to assess the bone conduction thresholds of operated ear following middle ear surgery at different follow up periods. Methods: 100 cases of chronic suppurative otitis media posted for middle ear exploration surgery were included in the study. Results: Sensorineural hearing loss was present in 3 cases out of 100 cases (3\%) after undergoing mastoid surgery. There was a mean increase in bone conduction thresholds of $0.75 \mathrm{~dB}$ at $500 \mathrm{~Hz}, 1.4 \mathrm{~dB}$ at $1 \mathrm{kHz}, 1.7 \mathrm{~dB}$ at $2 \mathrm{kHz}$ and $2.7 \mathrm{~dB}$ at $4 \mathrm{kHz}$ at $6^{\text {th }}$ month of follow up period after surgery with statistical significance at $2 \mathrm{kHz}(\mathrm{p}=0.011)$ and $4 \mathrm{kHz}(\mathrm{p}<0.001)$. Conclusion: Post mastoidectomy hearing loss is of high frequency in nature.
\end{abstract}

\section{Keywords}

Chronic Otitis Media, Mastoidectomy, Drill Induced Acoustic Trauma, SNHL

\section{Introduction}

Mastoid drilling is an inevitable part of mastoid exploration surgeries. Surgeons have always been concerned about the detrimental infliction on hearing while operating on the mastoid. Sensorineural hearing loss (SNHL) following ear surgeries has been documented in studies as early as 1960 (Schuknecht et al.) [1]. Since then many authors have investigated variables causing sensorineural loss 
after tympanomastoid surgeries and methods to prevent this undesired outcome. Mastoid surgeries undertaken for diseases of the middle ear cleft such as chronic suppurative otitis media and its complications, cholesteatoma, atticoantral diseases like retraction pockets, granulation and other pathologies of the middle ear like ear polyp and mucosal disease include tympanoplasty, mastoidectomy and antrostomy procedures. Modern day mastoid surgery make use of cutting and diamond burr for accessing the antrum and removing disease from the middle ear all of which subject the inner ear to inadvertent and excessive acoustic trauma [2]. Mastoid exploration surgeries involve use of instruments, vacuum suction, use of drill work with metallic burr and ossicular manipulations which all can lead to exposure of the labyrinth to excessive sound levels as well as vibrations which may, in turn, cause damage to the inner ear structures [3].

The incidence of permanent sensorineural hearing loss following tympanomastoid surgery is $1.2 \%-4.5 \%$ [2] [4]. Every time when a drill is used the ipsilateral cochlea is exposed to noise levels of about $100 \mathrm{~dB}$ and the contralateral cochlea to levels of 5 to $10 \mathrm{~dB}$ lower than the operative ear [5] [6]. In mastoid surgery higher levels of noise induced hearing loss are expected due to longer time of exposure to drill work. Possible noise trauma to the inner ear can only be avoided by minimizing the duration of drilling and thus the duration of the harmful noise exposure to the cochlea [6].

This study has been undertaken to evaluate the effect of middle ear surgery to the hearing mechanism of the ear, if it has an effect, to study in detail about the degree of hearing loss it causes, its progression over a period of 1 month, 3 months and 6 months in the post-operative period and whether it causes a temporary or permanent hearing loss.

\section{Materials and Methods}

This hospital based prospective study was carried out at Sawai Man Singh Medical College \& Hospital, Jaipur, India. A total of 100 cases of chronic suppurative otitis media undergoing tympanomastoid surgery were followed upto 6 months to study the proportion of sensorineural hearing loss following tympanomastoid surgery and to assess the mean bone conduction threshold of sensorineural hearing loss following surgery. The study was carried out for 21 months from April 2015 to December 2016. SNHL was defined as worsening of bone conduction thresholds to more than $30 \mathrm{~dB}$ at three consecutive frequencies. Patients of chronic suppurative otitis media requiring mastoid exploration were included in the study. Subjects with preoperative sensorineural hearing loss (SNHL), history of previous mastoid surgery, occupational noise exposure, history of ototoxic drug intake and non consenting subjects for the study were excluded from the study. Patient was evaluated with pure tone audiometry preoperatively. After careful evaluation, patients were posted for surgery at the institute operation theatre. Intraoperative ossicular finding, disease status and drilling duration were noted. Bone conduction thresholds were measured postopera- 
tively at first, third and sixth month post surgery. The subjects were divided into two groups, Group I with postoperative sensorineural hearing loss and group II with no affection of bone thresholds. The data was entered in excel spreadsheet and analysis was done using Statistical Package for Social Sciences (SPSS) version 21.0. Categorical data were presented as numbers (percent) and were compared among groups using Chi-square test. Quantitative variables were presented as mean \pm standard deviation and were compared using by students t-test, ANOVA Test and post Hoc Tukey Test to find out the most significant groups among all the groups. Paired analysis was evaluated by using paired t-test. A p-value less than 0.05 was considered statistically significant.

\section{Results}

Patient demographics, type of mastoidectomy performed and mean drilling time are summarised in Table 1. Among 100 cases of chronic SOM cases found eligible for the study, 62 were male and 38 females with mean age 26.28 years (range $=12$ - 50 years). The incidence of post operative SNHL was 3\% $(n=3)$ in our study. Cases were classified as active squamous (AS), active mucosal (AM), inactive squamous (IS) and inactive mucosal disease (IM) according to the disease type. There were 56, 12, 26 and 6 patients each of AS, AM, IS and IM disease respectively. The three cases that developed SNHL after surgery had active squamous disease with erosion of incus and an intact malleus and stapes. The most common ossicular finding was an eroded incus with grossly normal malleus and stapes with incudostapedial separation $(n=56)$ followed by a diseased incus and stapes suprastructure $(\mathrm{n}=30)$. Fifty-nine patients underwent canal wall down mastoidectomy and 41 patients underwent a posterior canal wall preserving surgery. There were no significant association found between development of SNHL and type of surgery. Significant association was observed between drilling time duration and development of SNHL post surgery. Proportion of SNHL was higher in patients subjected to prolonged drilling duration of more than 50 minutes.. Mean drilling duration in patients who developed SNHL was $63.33 \pm 5.774$ minutes as compared to patients with normal postoperative bone conduction thresholds (mean $=34.11 \pm 14.94$ minutes), $\mathrm{p}<0.001$ (Table 2). On Pearson's Correlation coefficient test, a positive correlation existed between drilling duration and bone conduction thresholds at all frequencies at the different follow up periods. The correlation was more significant in the first month for the frequencies $1 \mathrm{kHz}, 2 \mathrm{kHz}$ and $4 \mathrm{kHz}$ than the later months (Table 3).

On evaluating bone conduction thresholds after surgery in the follow up period, there was an increase in the mean bone conduction thresholds across all the tested frequencies at 1 month, $3^{\text {rd }}$ month and $6^{\text {th }}$ month compared to the preoperative audiometry (Table 4, Figure 1). On paired t-test, no significant differences in mean bone conduction thresholds were observed between preoperative and postoperative audiometry for frequencies $500 \mathrm{~Hz}$ and $1 \mathrm{kHz}$. Signifi- 
cant difference in mean bone conduction threshold were observed for $2 \mathrm{kHz}(\mathrm{p}$ $=0.01)$ and $4 \mathrm{kHz}(\mathrm{p}<0.001)$ at all three follow up periods compared to preoperative mean thresholds. There was a mean increase in bone conduction thresholds of $0.75 \mathrm{~dB}, 1.4 \mathrm{~dB}, 1.7 \mathrm{~dB}$ and $2.7 \mathrm{~dB}$ at $500 \mathrm{~Hz}, 1 \mathrm{kHz}, 2 \mathrm{kHz}$ and $4 \mathrm{kHz}$ respectively which was significant at $2 \mathrm{kHz}$ and $4 \mathrm{kHz}$ (Table 5).

Table 1. Demographics, procedure and mean drilling time of the subjects (Abbr., ICWM-Intact Canal Wall Mastoidectomy, CWDM-Canal Wall Down Mastoidectomy).

\begin{tabular}{lcccc}
\hline & & Group I $(\mathrm{N}=3)$ & Group II (N =97) & p-value \\
\hline \multirow{2}{*}{ Gender } & Male & 1 & 61 & 0.664 \\
& Female & 2 & 36 & \\
Mean Age (years) & $35.67 \pm 7.23$ & $25.96 \pm 10.58$ & 0.146 \\
Procedure & ICWM & 1 & 40 & 0.748 \\
& CWDM & 2 & 57 & \\
Mean Drilling time (min) & $63.33 \pm 5.774$ & $34.11 \pm 14.94$ & $<0.001$ \\
\hline
\end{tabular}

Table 2. Comparison of mean drilling duration among two groups.

\begin{tabular}{ccc}
\hline Category & Mean Drilling Duration (min) & Chi-Square \\
\hline Group I $(\mathbf{n}=\mathbf{3})$ & $63.33 \pm 5.774$ & \\
Group II $(\mathbf{n}=\mathbf{9 7})$ & $34.11 \pm 14.94$ & $17.526(\mathrm{p}<0.001)$ \\
Total & $34.99 \pm 15.56$ &
\end{tabular}

Table 3. Correlation coefficient ( $r$ ) of drilling duration with bone conduction thresholds at the follow up periods.

\begin{tabular}{cccc}
\hline Frequency $(\mathrm{Hz})$ & $\mathrm{r}$ for BC at 1 month & $\mathrm{r}$ for BC at 3 months & $\mathrm{r}$ for BC at 6 months \\
\hline 500 & 0.154 & 0.122 & 0.158 \\
1000 & 0.587 & 0.118 & 0.144 \\
2000 & 0.264 & 0.209 & 0.19 \\
4000 & 0.202 & 0.138 & 0.184 \\
\hline
\end{tabular}

Table 4. Mean bone conduction (BC) thresholds before surgery and at $1^{\text {st }}, 3^{\text {rd }}$ and $6^{\text {th }}$ month of follow up.

\begin{tabular}{ccccc}
\hline & $\begin{array}{c}\text { Mean BC } \\
\text { at } 500 \mathrm{~Hz}\end{array}$ & $\begin{array}{c}\text { Mean BC } \\
\text { at } 1000 \mathrm{~Hz}\end{array}$ & $\begin{array}{c}\text { Mean BC } \\
\text { at } 2000 \mathrm{~Hz}\end{array}$ & $\begin{array}{c}\text { Mean BC } \\
\text { at } 4000 \mathrm{~Hz}\end{array}$ \\
\hline Before Surgery & $11.75 \pm 5.19 \mathrm{~dB}$ & $11.90 \pm 5.06 \mathrm{~dB}$ & $13.95 \pm 4.34 \mathrm{~dB}$ & $13.60 \pm 4.15 \mathrm{~dB}$ \\
At $\mathbf{1}^{\text {st }}$ month & $12.85 \pm 5.61 \mathrm{~dB}$ & $13.40 \pm 5.68 \mathrm{~dB}$ & $15.80 \pm 5.67 \mathrm{~dB}$ & $15.85 \pm 5.03 \mathrm{~dB}$ \\
At $3^{\text {rd }}$ month & $12.55 \pm 5.53 \mathrm{~dB}$ & $13.25 \pm 5.48 \mathrm{~dB}$ & $15.65 \pm 5.16 \mathrm{~dB}$ & $16.12 \pm 4.56 \mathrm{~dB}$ \\
At $6^{\text {th }}$ month & $12.50 \pm 5.53 \mathrm{~dB}$ & $13.30 \pm 5.42 \mathrm{~dB}$ & $15.65 \pm 5.06 \mathrm{~dB}$ & $16.30 \pm 4.53 \mathrm{~dB}$ \\
\hline
\end{tabular}

$\mathrm{BC}=$ Bone conduction, $\mathrm{dB}=$ deciBels. 


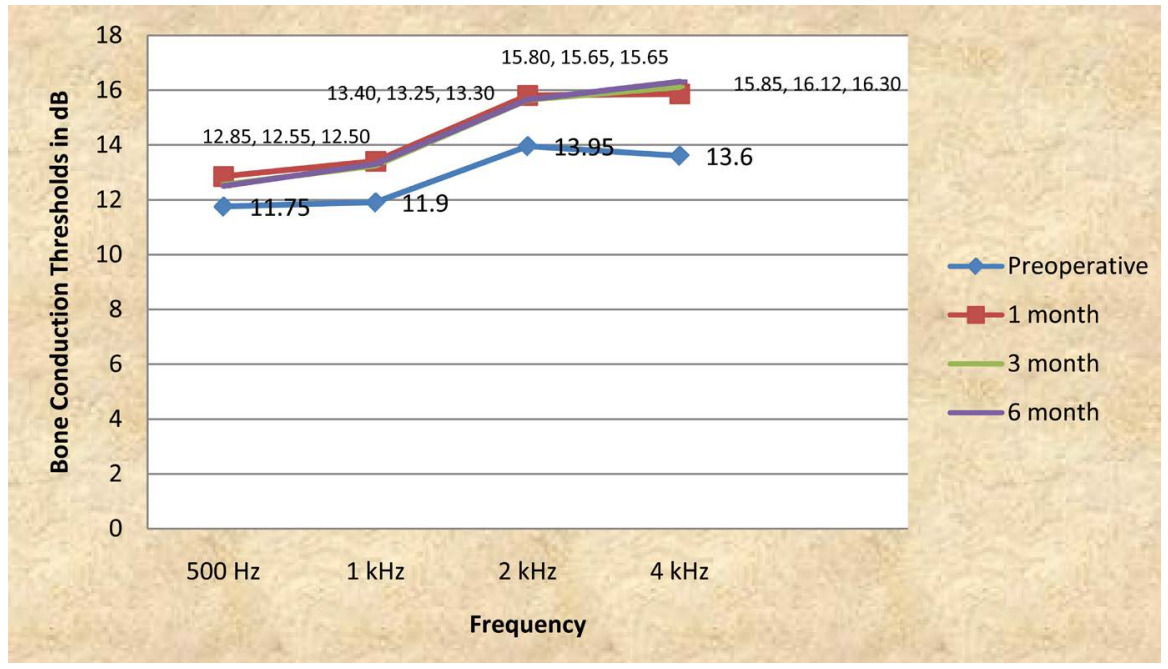

Figure 1. Comparison of bone conduction threshold between preoperative audiometry and postoperative audiometry.

Table 5. Mean increase in BC threshold at 6 months.

\begin{tabular}{ccc}
\hline Frequency $(\mathrm{Hz})$ & Mean increase in BC threshold $(\mathrm{dB})$ & p value \\
\hline 500 & 0.75 & 0.334 \\
1000 & 1.4 & 0.07 \\
2000 & 1.7 & 0.011 \\
4000 & 2.7 & $<0.001$ \\
\hline
\end{tabular}

\section{Discussion}

The incidence of postoperative sensorineural hearing loss ranges from $1.2 \%$ to $16.7 \%$ [1]-[11]. Acoustic trauma related hearing loss is sensorineural in nature. Temporary threshold shifts improve over 72 hours [12]. Variables such as type of mastoidectomy, type of burr used, its diameter and rotation speed, vacuum suction and irrigation, ossicular manipulation and experience of the operating surgeon have all been attributed to development of sensorineural hearing loss after mastoid exploration surgeries [13]-[18]. Every time a drill is used, the ipsilateral cochlea is exposed to noise levels of about $100 \mathrm{~dB}$ and the contralateral cochlea to levels of 5 to $10 \mathrm{~dB}$ lower than the operative ear [4] [5] [19]. Hong et al. recorded peak noise levels of more than $130 \mathrm{~dB}$ on drilling over endosteal membrane with diamond burr in cadaveric temporal bone dissection [20]. Holmquist, Kylen, Helms and other authors have studied that the sound pressure levels inner ear is exposed while working with drill burrs during cochleostomy and during accidental touch on an intact ossicular chain and concluded that inner ear could be exposed to sound pressure levels as high as $130 \mathrm{~dB}$ [4] [21] [22]. Iranfar et al. in their study points out that sensorineural hearing loss is temporary and the concern should be towards eradication of disease [23]. Vibration of the temporal bone at $250 \mathrm{~Hz}$ results in transmission of oscillation energy into the cochlea and its components since this is the resonant frequency [24]. 
Iranfar, Pignataro, Volter, Sakagam, Nadripour and their co-workers found out a significant difference in bone conduction threshold around the frequency of $250 \mathrm{~Hz}$ [23]-[28]. Whereas, Desai et al., Pal SK, Nikakhlagh and others found more significant affliction to frequencies above $2 \mathrm{kHz}$ [29] [30] [31]. In our study, we found drilling time to have a positive correlation in all frequencies from $500 \mathrm{~Hz}$ to $4 \mathrm{kHz}$ with significant correlation at $1^{\text {st }}$ month of follow up for 1 , 2 and $4 \mathrm{kHz}$. In later follow ups, significant correlation with drilling time was found only with $2 \mathrm{kHz}$. This could mean that mechanism for sensorineural hearing loss in mastoid surgery could be multifactorial in addition to acoustic trauma. In our study, highly significant deterioration of mean bone conduction thresholds was obtained at $4 \mathrm{kHz}$ followed by $2 \mathrm{kHz}$ and these changes were permanent by 1 month with no significant improvements in bone conduction thresholds at either $3^{\text {rd }}$ or $6^{\text {th }}$ month. Further studies are necessary to validate these findings at shorter duration follow up and with other audiological tests, such as otoacoustic emission, brainstem evoked response audiometry or cotical evoked response audiometry. We did not have necessary institutional clearance for OAE or BERA for this particular study.

\section{References}

[1] Schuknecht, H.F. and Tonndorf, J. (1960) Acoustic Trauma of the Cochlea from Ear Surgery. The Laryngoscope, 70, 479-505. https://doi.org/10.1288/00005537-196004000-00011

[2] Tos, M., Lau, T. and Plate, A. (1984) Sensorineural Hearing Loss Following Chronic Ear Surgery. The Annals of Otology, Rhinology, and Laryngology, 93, 403-409. https://doi.org/10.1177/000348948409300424

[3] Smyth, G.D. (1977) Sensorineural Hearing Loss in Chronic Ear Surgery. The Annals of Otology, Rhinology, and Laryngology, 86, 3-8. https://doi.org/10.1177/000348947708600102

[4] Palva, T., Karja, J. and Palva, A. (1973) High-Tone Sensorineural Losses Following Chronic Ear Surgery. Archives of Otolaryngology, 98, 176-178. https://doi.org/10.1001/archotol.1973.00780020184008

[5] Holmquist, J., Oleander, R. and Hallen, O. (1984) Peroperative Drill-Generated Noise Levels in Ear Surgery. Acta Oto-Laryngologica, 87, 458-460. https://doi.org/10.3109/00016487909126451

[6] Hickey, S.A. and O’Connor, A.F. (1991) Measurement of Drill-Generated Noise Levels during Ear Surgery. The Journal of Laryngology \& Otology, 105, 732-735. https://doi.org/10.1017/S0022215100117153

[7] Kylén, P., Stjernvall, J.E. and Arlinger, S. (1977) Variables Affecting the Drill-Generated Noise Levels in Ear Surgery. Acta Oto-Laryngologica, 84, 252-259. https://doi.org/10.3109/00016487709123964

[8] Ballantyne, J. (1970) Iatrogenic Deafness. The Journal of Laryngology \& Otology, 84, 967-1000. https://doi.org/10.1017/S0022215100072790

[9] Thorburn, I.B. (1971) The Pathogenesis of Chronic Otitis Media-A Clinical Study. Proceedings of the Royal Society of Medicine, 61, 395-399.

[10] Palva, A. and Sorri, M. (1979) Can an Operation on a Deaf Ear Be Dangerous for Hearing? Acta Oto-Laryngologica. Supplementum, 360, 155-157. 
[11] Domenech, J., Carulla, M. and Traserra, J. (1989) Sensorineural High-Frequency Hearing Loss after Drill-Generated Acoustic Trauma in Tympanoplasty. Archives of Oto-Rhino-Laryngology, 246, 280-282. https://doi.org/10.1007/BF00463575

[12] Kylén, P., Arlinger, S.D. and Bergholtz, L.M. (1977) Peroperative Temporary Threshold Shift in Ear Surgery. An Electrocochleographic Study. Archives of Oto-Rhino-Laryngology, 84, 393-401. https://doi.org/10.3109/00016487709123982

[13] Spencer, M.G. and Reid, A. (1985) Drill-Generated Noise Levels in Mastoid Surgery. The Journal of Laryngology and Otology, 99, 967-972. https://doi.org/10.1017/S0022215100098017

[14] Spencer, M.G. (1980) Suction Tube Noise and Myringotomy. The Journal of Laryngology and Otology, 94, 383-386. https://doi.org/10.1017/S0022215100088976

[15] Gjuric, M., Schneider, W., Buhr, W., Wolf, S.R. and Wigand, M.E. (1997) Experimental Sensorineural Hearing Loss Following Drill-Induced Ossicular Chain Injury. Acta Oto-Laryngologica, 117, 497-500. https://doi.org/10.3109/00016489709113427

[16] Jiang, D., Bibas, A., Santuli, C., Donnelly, N., Jeronimidis, G. and O'Connor, A. (2007) Equivalent Noise Level Generated by Drilling onto the Ossicular Chain as Measured by Laser Doppler Vibrometry: A Temporal Bone Study. Laryngoscope, 117, 1040-1045. https://doi.org/10.1097/MLG.0b013e3180459a10

[17] Al Anazy, F.H., Alobaid, F.A. and Alshiha, W.S. (2016) Sensorineural Hearing Loss Following Tympanoplasty Surgery: A Prospective Cohort Study. The Egyptian Journal of Otolaryngology, 32, 93-97. https://doi.org/10.4103/1012-5574.181083

[18] Cook, J.A., Krishnan, S. and Fagan, P.A. (1996) Hearing Results Following Modified Radical versus Canal-Up Mastoidectomy. Annals of Otology, Rhinology \& Laryngology, 105, 379-383. https://doi.org/10.1177/000348949610500510

[19] Parkin, J.L., Wood, G.S., Wood, R.D. and McCandless, G.A. (1980) Drill- and Suction-Generated Noise in Mastoid Surgery. Archives of Otolaryngology, 106, 92-96. https://doi.org/10.1001/archotol.1980.00790260024008

[20] Hong, Y.U., Tong, B., Zhang, Q., Zhu, W. and Duan, M. (2014) Drill-Induced Noise Level during Cochleostomy. Acta Oto-Laryngologica, 134, 943-946. https://doi.org/10.3109/00016489.2014.927591

[21] Kylén, P. and Arlinger, S. (1976) Drill-Generated Noise Levels in Ear Surgery. Acta Oto-Laryngologica, 82, 402-409. https://doi.org/10.3109/00016487609120925

[22] Helms, J. (1976) Acoustic Trauma from the Bone Cutting Burr. The Journal of Laryngology \& Otology, 90, 1143-1149. https://doi.org/10.1017/S0022215100083225

[23] Iranfar, K.H. and Iranfar, S.H. (2009) Does Surgery of Chronic Otitis Media Cause Sensorineural Hearing Loss? Pakistan Journal of Medical Sciences, 25, 972-975.

[24] Zou, J., Pyykko, I., Sutien, P. and Topilla, E. (2005) Vibration Induced Hearing Loss in Guinea Pig Cochlea: Expression of TNF- $\alpha$ and VEGF. Hearing Research, 202, 13-20. https://doi.org/10.1016/j.heares.2004.10.008

[25] Pignatero, L., Cappacio, P. and Laghis, A. (2001) Myringoplasty in Children: Anatom, Coland Functional Result. The Journal of Laryngology \& Otology, 115, 369-374.

[26] Volter, C., Baier, G., Schon, F., Muller, J. and Helms, J. (2000) Inner Ear Depression after Middle Ear Interventions. Laryngorhinoologie, 79, 260-265.

[27] Sakagm, M., Agasawara, H., Node, M., See, T. and Mishiro, Y. (1997) Sensorineural Hearing Loss Caused by Middle Ear Surgery. Nippon Jibiinkoka Gakkai Kaiho, 100, 740-746. https://doi.org/10.3950/jibiinkoka.100.740

[28] Nadripour, M. (2005) Sensorineural Hearing Loss after Middle Ear Surgery. Ardabil 
Medical Sciences Journal, 4, 362-366.

[29] Desai, A.A., Aiyer, R.G., Pandya, V.K. and Nair, U. (2004) Post Operative Sensorineural Hearing Loss after Middle Ear Surgery. Indian Journal of Otolaryngology and Head \& Neck Surgery, 56, 240-242.

[30] Pal, S.K. (2014) Evaluation of the Effect of Drilling on Hearing in Ear Surgery. State Journal of Otolaryngology, 21-24.

[31] Nikakhlagh, S., Saki, N. and Rahim, F. (2016) A Study on the Effects of Drilling in Rympanomastoid Surgery. International Journal of Pharmaceutical Research and Allied Sciences, 5, 175-178. 